\title{
Register til 23. årgang 1991
}

\section{Artikler}

Albæk, Erik, Den politiske dagsorden - en skraldespand? AIDS som illustrativ case

4: $396-417$

Bertramsen, René Bugge, Samfundsstyret vakst: 1990'ernes danske vokstmodel

Christiansen, Peter Munk og Palle Svensson, Indledning

Elklit, Jørgen, Faldet i medlemstal i danske politiske partier. Nogle mulige årsager

Hansen, Hanne Foss, Programevaluering: Videnskab eller politik?

Hansen, Karin, Det institutionelle perspektiv inden for den politiske videnskab

Jensen, Carsten, Omstilling i Danmark og Storbritannien

Jensen, Henrik S., Struktur-/aktorproblemet og hovedtraditioner $i$ politisk teori

Kastberg, Claus, Fra plan til marked: Økonomisk reform belyst ud fra de polske erfaringer, 1989-1990

Lomborg, Bjørn, Rationalitetsantagelsen $i$ samfundsvidenskaberne

Mortensen, Nils, Modsctninger og forsoninger mellem strukturer og aktorer

Mortensen, Nils, Indledning

Mouritzen, Poul Erik, Er inkrementalismen kun til de gode tider?

Nannestad, Peter, "Rational choice«-teori og studiet af økonomisk politik - en oversigt

Nedergaard, Peter, Public choice og europaisk integration $i$ 1980'erne

Nørgaard, Ole, Indledning

Nørgaard, Ole, De post-stalinistiske samfund og demokratiet

Skak, Mette, Centraleuropas nye udenrigspolitik

Sørensen, Curt, Den historiske materialisme i lyset af nyere diskussion om social handlen og social objektivitet

Winter, Søren, Udviklingen i beslutningsprocesteori: en introduktion

2: $167-184$

2: $133-135$

1: $60-83$

1: $84-100$

2: $136-153$

2: $185-196$

1: $\quad 7-19$

3: $259-274$

3: $307-326$

1: 42- 59

1: 5- 6

4: $375-395$

4: $418-430$

2: $154-166$

3: $237-240$

3: $241-258$

3: $275-291$

1: $\quad 20-41$

4: $357-374$

\section{Debat}

Berg, Sven, Några synspunkter på ekologisk inferens och kommentarer till en bok

Christensen, Erik, Politik og paradigmeskift. Replik til Uffe Østergaard

2: $200-205$

Glans, Ingemar, En kritisk diskussion av svenska data

4: $444-450$ 
Pedersen, Mogens N., Klarer han pynten? Logit-metoden mellem forenklingens Scylla og realiteternes Charybdis

4: $440-443$

Nielsen, Hans Jørgen, Er økologisk metode så dårlig, som Thomsen og Berglund siger?

4: $451-454$

Thomsen, Søren Risbjerg, Svar på kommentarer til "Modern Political Ecological Analysis"

Østergaard, Uffe, Fra Lenin til Logstrup. Kommentarer til Erik Christensen "Nye vardier i politik og samfund. Paradigmeskift og kulturbrydninger«

4: $455-463$

2: $197-200$

\section{Anmeldelser og bognoter}

Basse, Ellen Margrethe (red.), Regulering og styring 1 - en juridisk teori- og metodebog, 1989. (Ove K. Pedersen)

Basse, Ellen Margrethe og Vibeke Jensen (red.), Regulering og styring 2 - til fornyelse af den juridiske teori og metode, 1990. (Ove K. Pedersen)

Bender, John, Opbrud i Østeuropa, 1990. (Hans-Henrik Holm)

Bergsen, Helge O. og Anne Kristin Sydnes (eds.), Naive Newcomer or Shrewd Salesman?, 1990. (Niels Chr. Sidenius)

3: $327-330$

Boulding, Kenneth, Three Faces of Power, 1990. (Georg Sørensen) Bowman, John R., Capitalist Collective Action. Competition, Cooperation, and Conflict in the Coal Industry, 1989. (Niels Chr. Sidenius)

Brødsgaard, Kjeld Erik, Spillet om Kina, 1990. (Hans-Henrik Holm)

Grus, nr. 31, 11. årgang (Hans-Henrik Holm)

Cerny, Philip G., The Changing Architecture of Politics, 1990. (Henning Jørgensen)

Christensen, Jørgen Grønnegård, Den usynlige stat, 1991. (Bo Rothstein)

Dahl, Robert A., Democracy and its critics, 1989. (Ulrich Lauridsen)

Dalberg-Larsen, Jørgen, Lovene og livet, 1990. (Søren Peter Iversen)

Damgaard, Erik (red.), Dag Anckar, Hilmar Rommetvedt, Anders Sannerstedt, Mats Sjölin, Parlamentarisk forandring $i$ Norden, 1990. (Lars Bille)

Demokrati og makt $i$ Sverige, Maktutredningens huvudrapport, 1990. (Ove K. Pedersen)

Djupsund, Göran og Lars Svåsand (red.), Partiorganisasjoner: Studier i strukturer og prosesser i finske, norske og svenske partier, 1990. (Lars Bille)

Dumbrell, John, The Making of US Foreign Policy, 1990. (Nikolaj Petersen)

3: $327-330$

3: 344

3: 346

4: $464-465$

2: $206-207$

1: 120

1: 120

3: $330-333$

3: $333-335$

1: $101-102$

1: $102-104$

1: $105-107$

1: 107-109

4: $465-468$

1: $120-121$ 
Fonsmark, Henning, Den suverane dansker - et idepolitisk essay om det optimale demokrati, 1990. (Palle Svensson)

3: $336-338$

Friisberg, Claus, En verden i forandring. Historien efter 1945, 1990. (Arne Larsen)

1: $110-112$

Frost, Lis, Deregulering. Ret uden regler?, 1990. (Johannes Michelsen)

Garson, Robert og Christopher J. Bailey, The uncertain power, (Thomas Petersen)

Giddens, Anthony, The Consequences of Modernity, 1990. (Lars Bo Kaspersen)

Gundelach, Peter, Nils Mortensen og Jens Chr. Tonboe (red.), Sociologi under forandring, 1990. (Sven E. Olsson)

Hansen, Carsten Svane, De Tolv $i$ det indre marked, 1990. (Thomas Petersen)

Hansen, Poul Erik og Carsten Lunding, Dansk erhvervsliv, 1991. (Niels Chr. Sidenius)

Hansen, E. Damsgård, Kaj Kjærsgaard og Jørgen Rosted, Dansk okonomisk politik. Teorier og erfaringer, 1990. (Niels Chr. Sidenius)

Heisler, Martin O. (ed.), The Annals of the American Academy of Political and Social Science, 1990. (Niels Amstrup)

Hermansson, Jörgen, Spelteoriens nytta. Om rationalitet $i$ vetenskap och politik, 1990. (Peter Nannestad)

Jensen, Mogens Kjær, Kvalitative metoder $i$ anvendt samfundsforskning, 1991. (Ole Steen Kristensen)

Kitaj, Torben, Østeuropa $i$ kort og tal, 1991. (Mette Skak)

Kristensen, Jens Pagter og Steen Ryd Larsen, EF og international økonomi, 1991. (Niels Chr. Sidenius)

Lennert, Charles C. Intellectuals and Politics. Social Theory in a Changing World, 1991. (Kurt Aagaard Nielsen)

Myers, Norman (red.), Gaia - det globale miljøatlas, 1990. (Niels Chr. Sidenius)

Nationalitetsproblemerne i Sovjetunionen, 1990. (Mette Skak)

Nedergaard, Peter, EF's markedsintegration, 1990. (Martin Paldam)

Nielsen, Henrik Skovgaard, Flemming Schmidt, Nils Arne Sørensen, Niels Kayser Nielsen, Verdens Historie 3. Fra 1945 til 1990, 1990. (Arne Larsen)

Olsen, Gorm Rye, Golfkrisen og den nye verdensorden, 1991. (Hans-Henrik Holm)

Pearce, David W. og R. Kerry Turner, Economics of Natural Resources and the Environment, 1990. (Peter Andersen og Jørgen Birk Mortensen)

Petersen, Nikolaj, EF, den politiske union og Danmark, 1991. (Niels Chr. Sidenius)

2: $207-209$

1: 121

1: $112-114$

4: $468-470$

1: $121-122$

3: 345

$1: 122$

2: $209-210$

2: $210-211$

2: $211-213$

3: $338-340$

3: 345

3: $340-343$

1: 122

1: 118

2: $213-216$

2: $217-218$

3: 344

2: $218-220$

3: $344-345$ 
Rasmussen, Hanne og Mogens Rüdiger, Danmarks historie, bind 8, "Tiden efter 1945", 1990. (Arne Larsen)

2: $220-222$

Schmidt, Erik Ib, Behøver vi at nå det hele?, 1990. (Jørn Loftager) 1: 114-116

Smith, Graham, The Nationalities Question in the Soviet Union, 1990. (Mette Skak)

1: $116-118$

Svennevig, Palle, Dansk Økonomisk Bibliografi 1988-1989, 1991. (Svend Hylleberg)

2: $222-223$

Sørensen, Peter Birch og Bent Rold Andersen, Finansiering af de offentlige udgifter $i$ Danmark i 1990'erne, 1990. (Gunnar Thorlund Jepsen)

Thomsen, Jens, Det europaiske monetare samarbejde, 1990. (Hans Berend Feddersen) 